\title{
Comparative Study of Hardfacing of AISI 1020 Steel by Gas Welding and Tig Welding Processes
}

\author{
G.R.C. PRADEEP ${ }^{1}$,Dr. A. RAMESH ${ }^{2}$,Dr. B. DURGA PRASAD ${ }^{3}$ \\ ${ }^{I}$ (Research Scholar, Dept of Mechanical Engg, JNTUA, Anantapur, India \& Associate Professor, Dept of \\ Mechanical Engg, Gates Institute of Technology, Gootyanantapuram (Vill), Gooty, Anantapur, India \\ ${ }^{2}$ (Principal, Gates Institute of Technology, Gootyanantapuram (Vill), Gooty, Anantapur, India \\ ${ }^{3}$ (Associate Professor, Dept of Mechanical Engg, JNTUCEA, Anantapur, India
}

\begin{abstract}
Weld hardfacing techniques are employed mainly to extend or improve the service life of engineering components either by rebuilding or by fabricating in such a way as to produce a metallic/alloy wall section to combat wear, erosion, corrosion, etc. In this paper, an attempt has been made to determine the better welding process to hardface AISI 1020 steel based on wear study. Two different welding processes - Gas Welding and Tungsten Inert Gas Welding (TIG) have been compared. Based on the study, the specimens prepared using TIG welding process yielded better wear properties compared to the specimens' prepared using Gas Welding process till $1.256 \mathrm{~m} / \mathrm{s}$ sliding velocity. The Gas Welding process yielded better wear properties for sliding velocities above $1.571 \mathrm{~m} / \mathrm{s}$. An attempt was made to interpret the factors contributing to achieve the said results.
\end{abstract}

Keywords - AISI 1020, Hardfacing, Welding, Wear resistance

\section{INTRODUCTION}

Hardfacing, also known as "Hardsurfacing", is the application of build-up of deposits of specialized alloys by means of welding process to resist abrasion, corrosion, high temperature, or impact. Such an alloy may be deposited on the surface, an edge, or merely the point of a part subject to wear [1]. Welding deposits can functionalize surfaces and reclaim components extending their service life [2]. Welding is a key technology to fulfil these requirements and to apply hardfacing alloys [3].

A hard-faced part should be thought of as a laminate, with the base material selected for strength and economy, and the hard-facing material (which might be unsuitable as well as too costly for use in fabricating the complete part) selected for the specific wearing conditions to which the critical sections of the part will be subjected in service. Hardfacing may be applied to a new part during its production, or it may be used to restore a worn-down surface. Hard-facing increases the service life of a part and there by extend the lifetime of machinery equipment efficiently [3].

Core components such as crushers are exposed to heavy wear and require efficient surface protection measures to avoid costly downtimes and to reduce costs for expensive spare parts [3]. This process has been adopted across many industries such as Cement, Mining, Steel, Petro-chemical, Power, Sugar cane and Food [3].In recent years, weld hardfacing processes have been developed rapidly and are now applied in numerous industries, e.g., chemical and fertilizer plants, nuclear and steam power plants, pressure vessels and agriculture machines, railways, and even in aircraft and missile components [4]. Hardfacing is primarily done to enhance the surface properties of the base metal [5].

\section{HARDFACING PROCESSES USED}

Hardfacing can be applied by a number of welding processes. Selection of the most suitable welding process for a given job will depend on a number of factors like: Nature of Work to which the component to be Hard-faced is subjected to, Function of the component, Base metal composition, Size and shape of component, Accessibility of Weld equipment, State of repair of worn components, Number of same or similar items to be hard-faced and cost of replacement of the part etc. [1].There are various processes for Hardfacing.

The following processes are adopted for the present study based on dilution effect caused by the welding process on the base metal:

- Hardfacing by Gas Welding - Deposition by Oxy-Acetylene Gas Welding [6].

- Hardfacing by combination of Arc and Gas - Tungsten Inert Gas Welding [7]. 


\section{BASE MATERIALAND WELD CONSUMABLE USED IN HARDFACING}

Steel comprises almost $85 \%$ of the metal produced and used in most applications. The Low-Carbon Steels and Low-Alloy Steels used in the industry for making different components for different applications include the AISI series C-1008 to C-1020, 2315, 2515, and 2517 [8,9,10,11]. These steel series generally have, Carbon ranging from 0.10 to $0.25 \%$, manganese ranging from 0.25 to $1.5 \%$, phosphorous of $0.4 \%$ maximum, and sulfur of $0.5 \%$ maximum. Steels in this range are most widely used for industrial fabrication and construction. These steels can be easily welded with any of the arc, gas, and resistance welding processes.

The other low-alloy high-strength steels that represent the bulk of the remaining steels in the AISI designation system include the low-manganese steels, the low-to-medium nickel steels, the low nickelchromium steels, the molybdenum steels, the chromium-molybdenum steels, and the nickel-chromiummolybdenum steels $[8,9,10,11]$. These alloys are included in AISI series 2315, 2515, and 2517. Carbon ranges from $0.12-0.30 \%$, manganese from $0.40-0.60 \%$, silicon from $0.20-0.45 \%$ \& nickel from $3.25-5.25 \%$.

In the present study AISI1020 steel has been used for Base material as well as for the Weld Consumable. In the present study same material as that of the base material is used for deposition with different welding processes to facilitate easy assessment of the effect of different welding process on wear of hard-faced component.

\section{SAMPLE PREPARATION AND TESTING}

The material used for the sample preparation is AISI 1020 steel. The chemical composition, physical and mechanical properties of the material are given below:

Table 1: Chemical Composition of AISI 1020 Steel by Wt \%

\begin{tabular}{|l|c|c|c|c|c|}
\hline Element & $\mathrm{C}$ & $\mathrm{Mn}$ & $\mathrm{P}$ & $\mathrm{S}$ & $\mathrm{Fe}$ \\
\hline Composition (\%) & $0.18-0.23$ & $0.30-0.60$ & 0.04 (Max) & 0.05 (Max) & Balance \\
\hline
\end{tabular}

Table 2: Physical and Mechanical Properties of AISI 1020 Steel

\begin{tabular}{|l|c|c|c|c|c|}
\hline Property & $\begin{array}{c}\text { Elastic Modulus } \\
(\mathrm{GPa})\end{array}$ & $\begin{array}{c}\text { Density } \\
\left(\mathrm{x} 10^{3} \mathrm{Kg} / \mathrm{m}^{3}\right)\end{array}$ & $\begin{array}{c}\text { Poisson's } \\
\text { Ratio }\end{array}$ & $\begin{array}{c}\text { Hardness } \\
(\mathrm{HB})\end{array}$ & $\begin{array}{c}\text { Tensile Strength } \\
(\mathrm{MPa})\end{array}$ \\
\hline Value & $190-210$ & $7.7-8.03$ & $0.27-0.30$ & 111 & 394.7 \\
\hline
\end{tabular}

Test samples are prepared as per ASTM standards. AISI 1020 round rods of diameter 10mm are taken and cut in to cylinders of required lengths as per ASTM standards. The sample pieces are thoroughly cleaned to remove oil and dirt. The faces are finished by removing the burr to maintain flat surface. Weld deposit is done with AISI 1020 filler rods of diameter $2 \mathrm{~mm}$ on the flat face of each sample using two different methods namely, Gas Welding (Oxy- Acetylene Welding) and TIG welding (with Argon as Inert Gas). Turning is done with fine cuts to get smooth cylindrical finish and maintain the required size as per ASTM standards. The faces are smooth finished, for perfect contact on POD machine, by holding the sample in drilling machine and rubbing on sand belt machine. The Weld deposit height is maintained at least $5 \mathrm{~mm}$ in the total sample length as shown in Fig. 1.

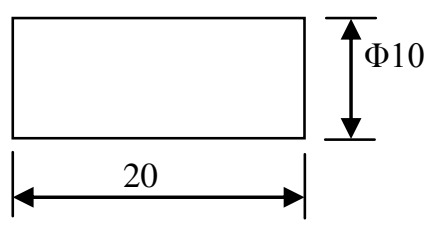

Before welding

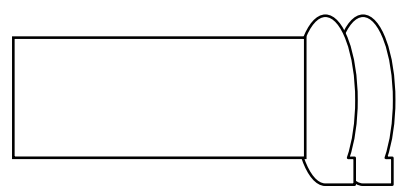

After welding

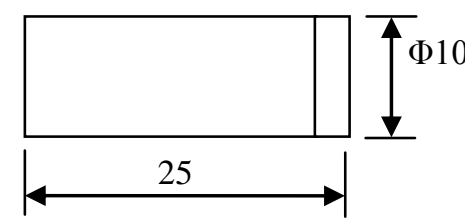

After Turning \& Finishing

Fig 1: Steps in Sample Preparation

Computerized Pin on Disc Wear testing Machine with the sample as test material and High Carbon EN31 steel (HRC 60) as counter-surface equipped with LVDT and digital display system was used to record the wear height loss.

\section{RESULTS AND DISCUSSION}

The Plain Sample without welding, Gas Welded Sample and TIG Welded Sample are tested on the POD machine to find out the wear characteristics at different sliding distances and different loads. Three Sliding 
Velocities of $0.9426 \mathrm{~m} / \mathrm{s}, 1.256 \mathrm{~m} / \mathrm{s}, 1.571 \mathrm{~m} / \mathrm{s}$ were chosen for the test. The load was varied from $9.81 \mathrm{~N}$ to $49.05 \mathrm{Nin}$ steps of $9.81 \mathrm{~N}$. Each sample was tested for different sliding distances from $282.78 \mathrm{~m}$ to $2827.8 \mathrm{~m}$ in steps of $94.26 \mathrm{~m}$. The average of 8 readings were considered for calculation of Wear Volume, Wear Factor and Frictional Coefficient and plotted on the graphs. The sample of the graphs obtained for a particular sliding velocity and load is shown in the Fig. 2, 3, 4 .

\subsection{Effect on Wear Volume}

It was observed (Fig. 2) from the results that at Sliding Velocity of $0.9426 \mathrm{~m} / \mathrm{s}$, the values of the wear volume for Plain sample without welding (Base metal) and the Gas welded sample are very close, but TIG welding sample was showing better wear properties. Further it was observed that at higher Sliding Velocities (above $1.256 \mathrm{~m} / \mathrm{s}$ ) the values of Gas Welding Sample and TIG welding Sample were observed to be very close, but TIG welding sample was showing better wear properties. Though \% Dilution is less in Gas Welding compared to TIG Welding, may be the narrow heat affected zone of higher hardness than the base material in TIG welding might have offered resistance to wear and resulted in enhanced wear properties at lower sliding velocities. However the wear properties of Gas welded samples at higher sliding velocities of $1.571 \mathrm{~m} / \mathrm{s}$ were enhanced compared to TIG Welding samples. This may be due to broader heat affected zone of higher hardness than the base material in Gas welding which might have offered resistance to wear and resulted in enhanced wear properties at higher sliding velocities. At higher velocities, the narrow heat affected zone of higher hardness in TIG welding might have reduced the resistance to wear. At higher sliding velocities and higher loads the heat generation is higher, which makes the metal peel out in the form of chips.

\subsection{Effect on Wear Factor}

It was observed (Fig. 3) from the results that at Sliding Velocity of $0.9426 \mathrm{~m} / \mathrm{s}$, the values of the wear Factor for TIG welding sample were better than Gas welded sample. Further it was observed that at higher Sliding Velocities (above $1.256 \mathrm{~m} / \mathrm{s}$ ) the values of Gas Welding Sample and TIG welding Sample were observed to be very close, but TIG welding sample was showing better wear factor values. However the wear factor of Gas welded samples at higher sliding velocities of $1.571 \mathrm{~m} / \mathrm{s}$ were enhanced compared to TIG Welding samples.

\subsection{Effect on Friction Coefficient}

It was observed (Fig. 4) from the results that at Sliding Velocity of $0.9426 \mathrm{~m} / \mathrm{s}$, the values of the Friction Coefficient for TIG welding sample were higher than Gas welded sample. However the Friction Coefficient values of Gas welded samples at higher sliding velocities of above $1.256 \mathrm{~m} / \mathrm{s}$ were enhanced compared to TIG Welding samples. Further it was observed that at higher Sliding Velocities (above $1.571 \mathrm{~m} / \mathrm{s}$ ) the values of Gas Welding Sample and TIG welding Sample were observed to be very close, but Gas welding sample was showing higher friction coefficient values.

\subsection{SEM Micro Photographs}

Scanning Electron Microscopy, which is one of the conventional characterization techniques, was employed to study the nature of the wear surface of the welded samples. Micro photographs at 50x, 200x, 400x magnifications were taken. Few sample photographs are shown in figure 5. It can be seen clearly from figure 5 that at higher Sliding Velocities (above $1.256 \mathrm{~m} / \mathrm{s}$ ) the Gas Welding Sample wear surface was observed to show deeper plough marks and TIG Welding sample wear surface was observed to contain small chips and particles, showing that TIG welding sample has better wear properties compared to Gas welded sample. However at higher sliding velocities of $1.571 \mathrm{~m} / \mathrm{s}$ TIG Welding samples wear surface depicts deeper plough marks with delamination of surface layers compared to Gas welded samples. Hence the wear properties of Gas welded samples at higher sliding velocities of $1.571 \mathrm{~m} / \mathrm{s}$ were seen enhanced compared to TIG Welding samples. Hence the SEM microphotographs also support the discussion in the previous sections.

\subsection{Result Agreement with earlier researchers}

The results obtained are in close agreement with the earlier researchers who have compared different welding processes using AHP (Analytic Hierarchy Process Model) based on quantitative and qualitative factors, [12]. In their research it has been concluded that, based on both quantitative and qualitative factors, an integrated process measure (PM) for TIG welding was 0.2150 among the different processes to hardface carbon steels. The values of integrated process measure for other processes are lesser than TIG welding except PTAW.

Conventional weld hardfacing is done by Oxy-fuel welding, gas tungsten arc welding (GTAW/TIG), gas metal arc welding (GMAW/MIG), shielded metal arc welding (SMAW), and flux cored arc welding (FCAW) processes. Percentage dilution plays a major role in determining the properties of a hard-faced surface 
[5]. Dilution is defined as the percentage of base metal in the weld metal deposit. If the percentage of dilution is high, then the percentage of base metal in the weld metal deposit will be high and vice versa. At a higher percentage of dilution level, the surface properties are not enhanced to the expected level because of the presence of a higher amount of base metal. On the other hand, at a lower percentage of dilution level, the surface properties are much better compared to the base metal because of a low percentage of base metal in the deposited weld metal. Hence, the welding process which produces a low percentage of dilution is generally preferred for hardfacing applications [13]. The dilution factors for various processes are given below [14].

\subsection{Welding Process Dilution Factors}

Oxy-Acetylene Gas Welding

TIG Welding

Flux Cored Wire Arc Welding

Submerged Arc

$$
\begin{aligned}
& 0-5 \% \text { Dilution } \\
& 5-15 \% \text { Dilution } \\
& 20-45 \% \text { Dilution } \\
& 25-50 \% \text { Dilution }
\end{aligned}
$$

\section{CONCLUSIONS}

1. TIG welding samples were showing better wear properties than Gas welding samples till the Sliding velocity of $1.256 \mathrm{~m} / \mathrm{s}$ with various sliding distances and loads.

2. Gas Welding samples yielded better results at higher sliding velocities above $1.571 \mathrm{~m} / \mathrm{s}$ with various sliding distances and various loads compared to TIG Welded Samples.

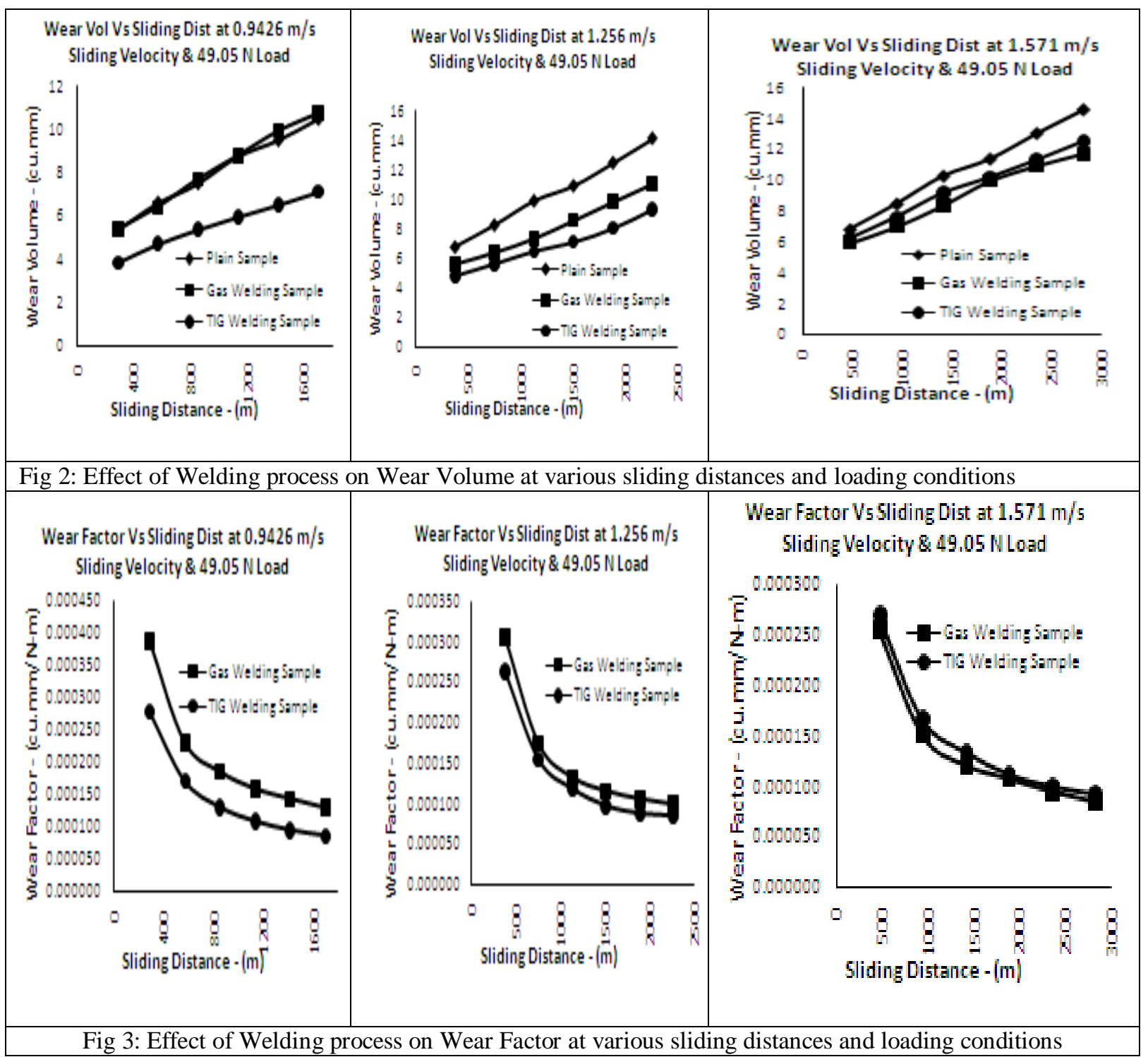




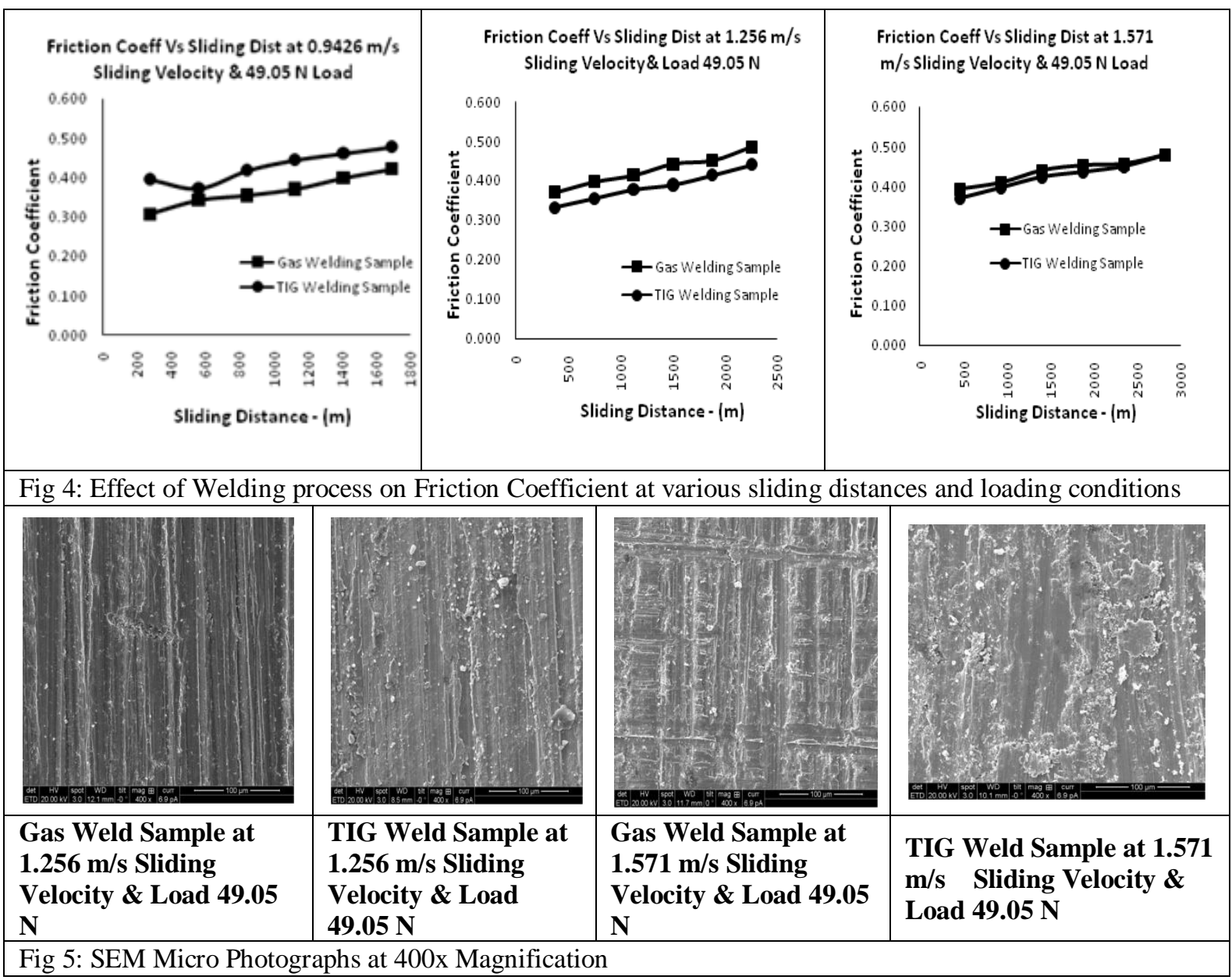

\section{REFERENCES}

[1] Pradeep GRC, Ramesh A, Durga Prasad B, (2010). A Review paper on Hardfacing Processes and Materials.International Journal of Engineering Science and Technology, Vol. X (XX), (1-5).

[2] AgustínGualco, Hernán G. Svoboda, Estela S. Surian and Luis A. de Vedia (2010). Effect of welding procedure on wear behaviour of a modified martensitic tool steel hardfacing deposit. Materials \& Design, Elsevier, Article in Press, Corrected Proof.

[3] Kirchgaßner, M., Badisch, E., Franek, F. (2008). Behaviour of iron-based hardfacing alloys under abrasion \& impact. Wear, Vol. 265(5-6), pp. 772-777.

[4] Richard LL (1990) Welding and welding technology. Tata McGraw-Hill, New Delhi

[5] Gourd LM (1998) Principles of welding technology. Viva Books,New Delhi

[6] Buchely, M.F., Gutierrez, J.C., León, L.M. and Toro, A. (2005). The effect of microstructure on abrasive wear of hardfacing alloys. Wear, Volume 259, Issues 1-6, pp. 52-61.

[7] Kashani, H., Amadeh, A., Ghasemi, H.M. (2007). Room and high temperature wear behaviors of nickel and cobalt base weld overlay coatings on hot forging dies. Wear, Volume 262, Issues 7-8, pp. 800-806.

[8] Wang, X.H., Han, F., Liu, X.M. Qu, S.Y., Zou, Z.D. (2008). Effect of molybdenum on the microstructure and wear resistance of Fe-based hardfacing coatings. Materials Science and Engineering: A, Vol. 489, Issues 1-2, pp. 193-200.

[9] Wang, X.H., Song, S.L., Zou, Z.D., Qu, S.Y. (2006). Fabricating TiC particles reinforced Fe-based composite coatings produced by GTAW multi-layers melting process. Materials Science and Engineering: A, Vol 441(1-2), pp. 60-67.

[10] Xin-hong Wang, Fang Han, Shi-yaoQu, Zeng-da Zou (2008). Microstructure of the Fe-based hardfacing layers reinforced by TiC-VC- $\mathrm{Mo}_{2} \mathrm{C}$ particles. Surface and Coatings Technology, Volume 202, Issue 8, pp. 1502-1509.

[11] Xinhong Wang, Fang Han, Xuemei Liu, ShiyaoQu, ZengdaZou (2008). Microstructure and wear properties of the Fe-Ti-V-Mo-C hardfacing alloy. Wear, Volume 265, Issues 5-6, pp. 583-589.

[12] V. Balasubramanian, R. Varahamoorthy, C. S. Ramachandran\& C. Muralidharan. (2009). Selection of welding process for hardfacing on carbon steels based on quantitative and qualitative factors. International Journal of Advanced Manufacturing Technology, Vol. 40, pp 887-897.

[13] Marimuthu K, Murugan N (2003) Prediction and optimization of weld bead geometry of PTA hardfaced valve seat rings. Surface Engineering, Vol. 19, pp143-149.

[14] Product Reference Manual - AFROX - Section -12 